\title{
The Evaluation of Mechanical Properties of Degraded Pet Bottles
}

\author{
Zdenka Džoganová ${ }^{1 *}$, Badida Miroslav ${ }^{2}$
}

1,2 Department of Environmental, Faculty of Mechanical Engineering, P. Komenského 5, 04200 Košice, Slovak Republic

\section{BIOGRAPHICAL NOTES}

Zdenka Džoganová, Ing. (born in 1987) is internal PhD. student at Department of Environmentalistics (since 2011) at Technical University of Kosice. Her research interest includes acoustics and psychoacoustics. She received M.Sc. degree in environmental engineering from Technical University of Kosice in 2011. She was the member in organization committee of ICEEE conference (International Council of Environmental Engineering Education) in 2011.

Miroslav Badida, Dr.h.c. prof. Ing. PhD. He is a graduate of Mechanical Faculty of Technical University of Košice. His scientific and research work focuses on the field of environmental engineering. An accent is put on the issue of environmental management systems, ecologization of products and their production and life cycle analysis of products. Lately his attention is paid on research in the field of physical factors of working and living environment.

\section{KEY WORDS}

PET bottles, mechanical properties, degradation.

\begin{abstract}
In this article is attention focused on mechanical properties of selected PET material, which test samples were made from PET bottles. Notice that is already used packaging material. Test samples were stored in environment degradation with higher temperature with the aim to simulate the term conditions in summer. The test samples were gradually picked from environment degradation in exactly specified time cycles. After that there was done the tensile test to determine mechanical properties of these test samples - yield strength, tensile strength and relative extension.
\end{abstract}

\section{Introduction}

Plastics have developed an amazing presence in our lives. From the most commonplace tasks to our most unusual needs, plastics increasingly have provided the performance in products that consumers want. In fact, if you woke up tomorrow and there were no plastics, you would be in for quite a shock. Life would be much more expensive and much less comfortable. And many of the conveniences you had come to take for granted would be gone. Mostly, though, you would be surprised at the many products that had vanished-things you had never thought of as being plastic. That's because, in just a few decades, consumers have come to consider the extraordinary properties of plastics as nothing out of the ordinary. Plastics' popularity and wide usage can be attributed to one basic fact: Because of their range of properties and design technologies, plastics offer consumer benefits unsurpassed by other materials. [1], [2], [3]

Plastics generally are organic high polymers, i.e. they consist of large chainlike mol- 
ecules containing carbon. They are formed in a plastic state either during or after their transition from a small-molecule chemical to a solid material. Stated very simply, the large chainlike molecules are formed by hooking together short-chain molecules of chemicals in a reaction known as polymerization. When units of a single monomer are hooked together, the resulting plastic is a homopolymer, such as polyethylene, which is made from the ethylene monomer. When more than one monomer is included in the process, for example, ethylene and propylene, the resulting plastic is a copolymer. [2]

Plastic products are after ending of their life-time transferred into waste which with its effects is the burden on the environment. One of the most popular plastic product and also plastic waste is the plastic bottle. Plastic bottles have the wide using as packaging for nonalcoholic drinks, also for food oils and motor oil.
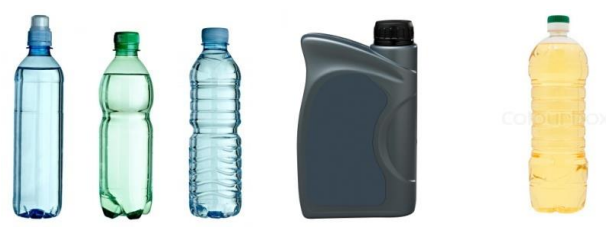

Fig. 1: Wide using of plastic bottles.

The time of natural decomposition of one plastic bottle is about 450 years. This process is supported by sun radiance, principally by ultraviolet radiance. Next one is the rain, temperature, wind and other weather factors. There is appreciable impact of chemicals and also mechanical aspects acting on the waste.

Plastic waste is generated in the production and processing of plastics as production waste and processing waste as well as municipal waste. The consumption of plastics is increasing every year in Europe about 3\% - 5\%. The global consumption of plastics increased in 1939 from one million ton up to 250 million ton in 2005 - Figure 1. [1], [2]

From 2009 to 2010 the global production of plastics increased by 15 million tonnes (6\%) to 265 million tonnes, confirming the long term trend of plastics production growth of almost 5\% per year over the past 20 years - Figure 2. In 2010 Europe accounted for 57 million tonnes (21.5\%) of the global production and China overtook Europe as the biggest production region at 23.5\%. [2]

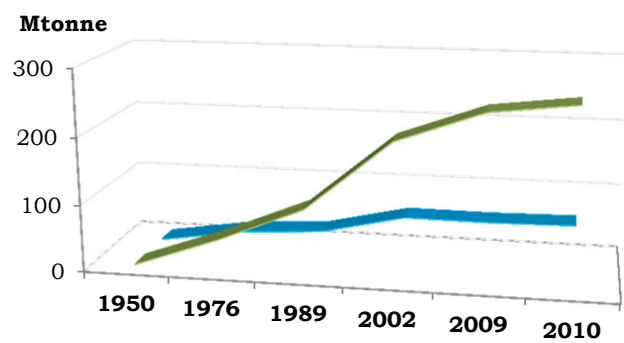

Fig. 2: World plastics production in years 1950-2010 [2].

The plastics industry also plays an important role in enabling growth through innovation in a wide range of key European industries such as automotive, electrical and electronic, building and construction and food and beverage sectors. [2], [3]

The most popular thermoplastic polyester nowadays is polycondensate terephthalic acid and ethylene glycol - the polyethylene terephthalate (PET). Much chemical resistance of PET is given by its organized structure. PET has good barrier properties against oxygen and carbon dioxide. PET exists both as an amorphous (transparent) and as a semi-crystalline (opaque and white) thermoplastic material. Generally, it has good resistance to mineral oils, solvents and acids but not to bases. The semi-crystalline PET has good strength, ductility, stiffness and hardness. The amorphous PET has better ductility but less stiffness and hardness. PET is globally recognized as a safe, recyclable packaging material. Numerous tests have created a broad scientific consensus that PET is non-toxic and is a safe material for the storage of food and beverages. Facts on PET support the efforts of regulators to ensure that plastics are safe for the public through scientific testing and analysis.Very important products of PET are fibers and foils. They have great resistance to abrasion, chemicals, weathering, aging and they are dimensionally stable. Polyethylene terephthalate fibers are used in production of industry fabric and textile fabric. [1], [4]

Degradation of plastics is possible to define like a file of physical and chemical processes ongoing at plastics and leading gradually to irreversible changes of their properties. We know natural and artificial degradation. By natural degradation we understand slow change of plastics properties by effect of the light, air, carbon dioxide and the wa- 
ter. At first, these changes limit the using of product and finally, they make it impossible at all. In the most of plastics aging is manifested by yellowing and increased fragility. The main cause of deteriorating of plastics properties and truncating their life are physical, physically-chemical and chemical influence of environment and also the biological degradation of polymers. The artificial degradation is defined as degradation of plastic at artificial conditions [5], [6].

Degradation is limited by life of product. The durability of material is the time, during which are important properties kept on the specified level, which is enough for the right function of product. It depends on material properties and conditions of product use. The self-degradation of polymers can be in progress in the cause of exposition of surface of polymers at sunlight, temperature, cold, chemical compounds or microorganisms. The polymer surface can be corrupted by next diffusion of external environment into polymer. Polymer can react with the environment. Because of reactions the diffusion products can occurs at polymers surface or they can be released into the environment [7], [8], [9].

Polymers are very heat sensitive. This sensitivity is caused by weak strength of covalent bonds which create the polymer structure. The effect of increased temperature of polymers can show in two ways. The first one is the softening of polymer or increasing the kinetic energy from received heat up to overcoming the attractive forces and after that the polymer behaves as a liquid. The second one is the structure change of polymer. Some polymers are broken down into low molecular products or into monomers without chemical change of structure - they depolymerize. [7], [10]

Raman scattering is a phenomenon resulting from the interaction between photons of incident light with atoms, which is passed vibration and rotational energy states of atoms or molecules, the scattered light has a different wavelength (or photon energy) than the incident radiation. [11]

The development of non-destructive testing in the field tests are emerging, testing and verification of the chemical composition of the plastic material using spectrometric analysis of materials. One of these tests is non-destructive test and verification properties using Raman spectroscopy, Figure 3. It is fast and very effective solution for rapid material identification and control. Material identification consists of a comparison of the unique molecular composition of the material and subsequent comparison with standard materials stored at the library materials databases. Determining the type and chemical composition of unknown plastic we can determine very quickly in a matter of minutes. [11]

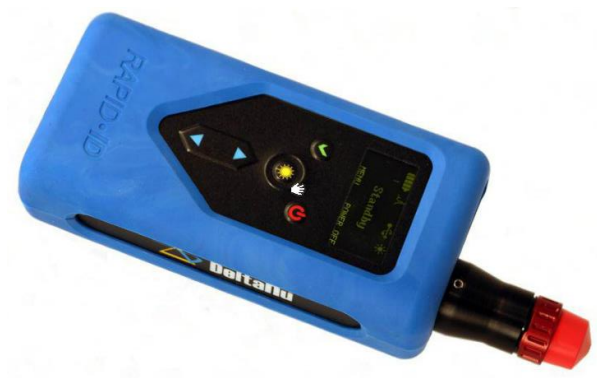

Fig. 3: DeltaNu, RAPID•ID [11].

\section{Materials and Method}

In experiments were used the plastics bottles mainly made from PET material. To production of test samples were chosen two types of used plastics bottles with different thickness and color. First group obtains transparent bottles with thickness about 0,16 mm (marked like white PET), second group obtains colored green PET bottles with thickness about 0,27 mm (marked like green PET). These samples different in color and thickness have similar composition as shows the Figure 4. Test samples from PET bottles were made by shearing in size 200 $\times 20 \mathrm{~mm}$ in 5 pieces in other environment and exposition in hot environment.

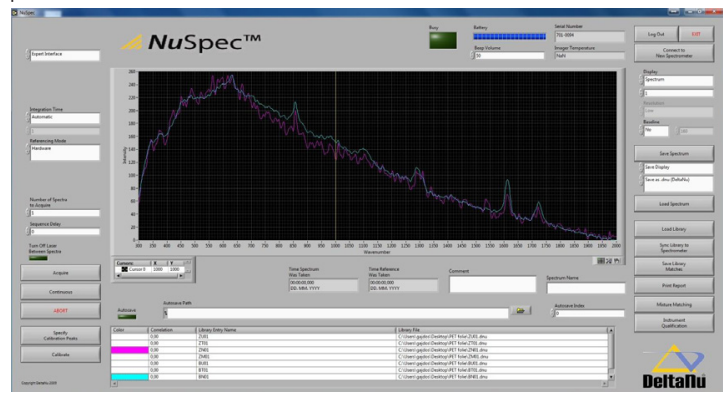

Fig. 4: The Raman's spectrum of white PET (blue) and green PET (pink)

Natural environment - test samples were saved in laboratory before test in test conditions, by the temperature $20 \pm 2^{\circ} \mathrm{C}$. Five test samples were exposed in environment with higher temperature for 
simulation environment in summer.

For simulation of environment in summer the test samples were exposed in environment with higher temperature $50 \pm 2^{\circ} \mathrm{C}$. The test samples positioned in this environment were exposed for 7 days, 14 days and 21 days (168 hours, 336 hours and 504 hours). This temperature was measured by contactless method by the type of pyrometer IRtec MicroRay HVAC. After individual days of exposition the static tensile test was made for test materials.

The main test to determine the mechanical properties - tensile test was chosen from spectrum of tests. In experiments was proceed under standard for finding tensile properties of plastics STN EN ISO 527-1 (64 0605). Tensile test was made by tensile test machine TIRA - test 2300.

Every test sample from natural environment and after selecting from degradation environment was caught in jaw of tensile machine and by speed of transom in $20 \mathrm{~mm} / \mathrm{min}$ it was tested until breaking. It was on mind by catching then axis of test sample was the same as tensile direction. On Figure 5 there is the sample in jaw of tensile machine during tensile test. After breaking test sample, the machine evaluated strength characteristics (yield strength, tensile strength and relative extension) by program.

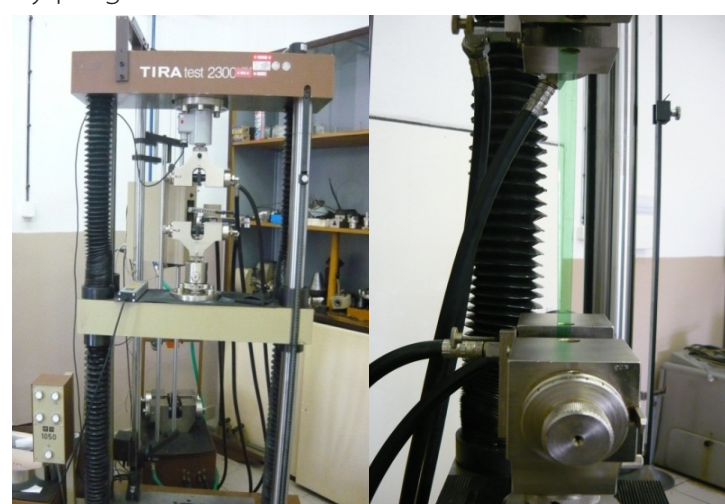

a) TIRA test 2300

b) The course of tensile test

Fig. 5: The tensile test machine(pink)

\section{Results}

The results from tensile test are noticed and created in graphs. Measured and calculated values of tensile test - yield strength $(\sigma Y)$, tensile strength $(\sigma \mathrm{M})$ and relative extension $(\varepsilon M)$ - from natural environment and from environment with higher temperature in time of exposition 7, 14 and 21 days are given on Table 1 and shown at Fig. 6 to Fig. 8.
Table 1: The average values of selected mechanical properties of test sample.

Appendix: NE - natural environment

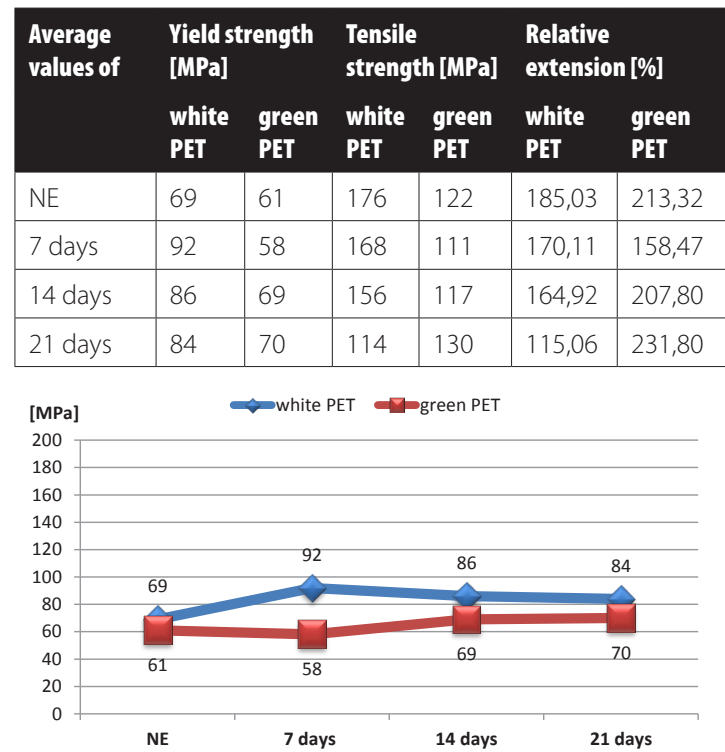

Fig. 6: The average values of yield strength of test samples in environment degadation.

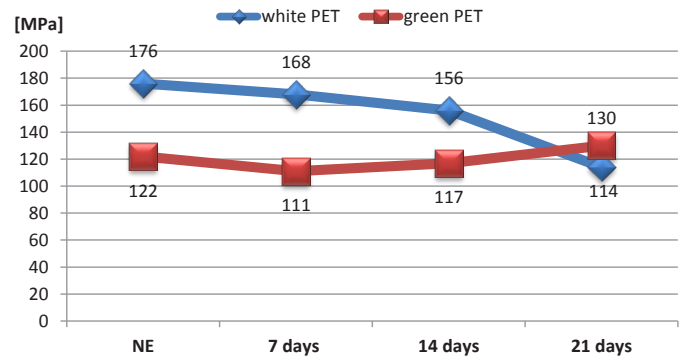

Fig. 7: The average values of tensile strength of test samples in environment degadation.

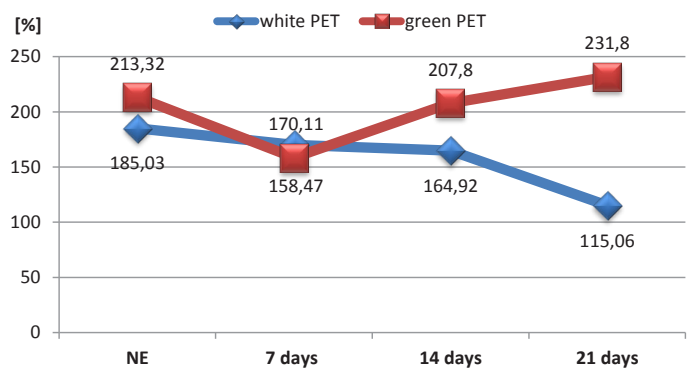

Fig. 8: The average values of relative extension of test samples in environment degadation. 


\section{Discussion}

Under experimental test for tensile properties determination of tested materials from environment degradation were given next conclusions:

- The yield strength value of exposed white PET material to higher temperature was about 6,5\% lower after 14 days of exposition and after 21 days of exposition was about 8,7\% lower in comparing with the measured value after 7 days of exposition. - The yield strength value of exposed green PET material to higher temperature was about $19 \%$ higher after 14 days of exposition and after 21 days of exposition was about 20,7\% higher in comparing with the measured value after 7 days of exposition.

- The tensile strength value of exposed white PET material to higher temperature after 14 days of exposition was about 7,1\% lower and after 21 days of exposition was about $32,1 \%$ lower in comparing with the measured value after 7 days of exposition.

- The tensile strength value of exposed green PET material to higher temperature after 14 days of exposition was about 5,4\% higher and after 21 days of exposition was about $17,1 \%$ higher in comparing with the measured value after 7 days of exposition.

- The relative extension value of exposed white PET material to higher temperature after 14 days of exposition was about 3,1\% lower and after 21 days of exposition was about 32,4\% lower in comparing with the measured value after 7 days of exposition.

- The relative extension value of exposed green PET material to higher temperature after 14 days of exposition was about 31,1\% higher and after 21 days of exposition was about 46,3\% higher in comparing with the measured value after 7 days of exposition.

\section{Conclusion}

The tested samples of both types tested PET material show interesting mechanical properties. While by white PET material exposed to higher temperature the values of mechanical properties degrease with increasing time exposition, by green PET material exposed to higher temperature get to increasing values of mechanical properties with increasing time exposition.

The increasing quantity of plastics waste relates to problems in environment and with health problem of population. As we know recycling is processing used materials into new products to prevent waste of potentially useful materials. It saves starting materials and also energy needed to produce new products. Under this results we can state than this materials is possible to recycle again because of it was not refer negative deterioration of mechanical properties of tested materials.

\section{Acknowledgements}

This paper has been prepared on the basis of the research project KEGA 049TUKE-4/2012.

\section{References}

[1] Badida, M. - Bosák, M. a kol.: Recyklácia a recyklačné technológie. TU, Košice, 2007. 623 s. ISBN 978-80-8073-946-1.

[2] Plastics: The Facts 2011, An analysis of European plastics production, demand and recovery for 2010, [2012-1128] available from: http://www.plasticseurope.org/documents/document/20111107101127-final_pe_factsfigures_ uk2011_Ir_041111.pdf

[3] Dulebová, L. - Badida, M.- Duleba, B.: Influence of environment on bending stress of composite with regranulate 2012. In: Annals of Faculty Engineering Hunedoara. Vol. 10., no. 2 (2012), p. 153-156. - ISSN 1584-2665.

[4] Liptáková, T. et al : Polymérne technické materiály, available from: http://kmi2.uniza.sk/wp-content/uploads/2010/10/ polymerne_konstrukcne_materialy.pdf

[5] Dulebová, Ĺ; Greškovič, F.: Vplyv plnív na vybrané vlastnosti plastov použivaných v elektrotechnickom priemysle, Transfer inovácií. Roč. (2009) č. 14, s. 172-176. ISSN 1337-7094. [cit. 2012-11-28]. Dostupné na internete: http://www.sjf.tuke.sk/ transferinovacii/pages/archiv/transfer/14-2009/pdf/172176.pdf

[6] Kruliš, Z. Et al.: Termoplasty v praxi, Verlag Dashofer, Praha, (2002)

[7] Ducháček, V.: Polymery - výroba, vlastnosti, zpracování, použití. Vysoká škola chemicko-technologická v Praze, ISBN 80-7080-617-6 PRAHA (2006)

[8] Honzík, R: Plasty se zkrácenou životností a způsoby jejich degradace. ISSN: 1801-2655. Dostupné na internete: http:// biom.cz/cz/odborne-clanky/plasty-se-zkracenou-zivotnosti-a-zpusoby-jejich-degradace

[9] Mechanical engineering : Degradation of Polymers. 2006 Available from: http://www.me.wpi.edu/People/Sisson/ Polymers/

[10] Encyclopedia of polymer science and technology: Degradation to magnetic polymers, Hoboken: Wiley-Inter science, Vol. 6, (2003). PP. 735. ISBN 0-471-28781-4

[11] http://www.intevac.com/intevacphotonics/deltanu/deltanu-products/portable-raman-spectrometers/rapid-id/ 